\title{
Associative history, not familiarity, determines strength of taste-aversion conditioning in thiamine-deficient rats
}

\author{
W. F. BUSKIST, H. L. MILLER, JR., D. E. FLEMING, and S. P. SPARENBORG \\ Brigham Young University, Provo, Utah 84602
}

\begin{abstract}
Two groups of rats (the recovery groups) were fed on a synthetic thiamine-deficient diet, and another group (the supplemented group) was fed on the same diet but received supplemental thiamine in their water so as not to become deficient. Following a 6-day recovery period during which all rats were given a novel-flavored thiamine-enriched diet, one recovery group and the supplemented group received injections of lithium chloride, and the remaining recovery group received injections of saline. Although all groups consumed similar amounts of the chocolate-enriched diet during the recovery period (i.e., all groups were approximately equally familiar with the enriched diet), only the supplemented/poisoned rats showed a marked taste aversion. These results confirm the existence of a "familiar-positive" class of foods and suggest that the context in which a rat is made familiar with dietary choice may overshadow the role of familarity per se as the determining factor in the development of food aversions and preferences.
\end{abstract}

The central focus of research investigating learning mechanisms in food selection has been the associative relationship between the coincidence of certain food cues (e.g., flavor) and the onset of subsequent toxicosis (Barker, Best, \& Domjan, 1977; Milgram, Krames, \& Alloway, 1977). There is, however, a burgeoning interest in the relationship between food cues and the beneficial effects of ingestion such as recovery from vitamin deficiency (Buskist, Miller, Duncan, \& Fleming, 1980; Zahorik, 1977). For example, it has been shown that rats prefer flavors paired with recovery from deficiency (Garcia, Ervin, Yorke, \& Koelling, 1967) and that "recovery" flavors are generally preferred to novel flavors (Zahorik \& Maier, 1969). More recently, Buskist et al. (1980) and Zahorik and Bean (1975) have shown that flavors paired with recovery from thiamine deficiency are resistant to aversion when those flavors are later paired with toxicosis. Thus while there is ample evidence to support the existence of three general classes of food (i.e., novel, or foods that have never been sampled; familiar-safe, or foods that have been ingested without any unpleasant consequences; and familiar-aversive, or foods that have been paired with toxicosis), Zahorik (1977) asserts that such recovery foods constitute a fourth category, familiar-positive, in which foods have been paired with the beneficial effects of ingestion such as recovery from illness.

According to Buskist et al. (1980), the resistance of recovery foods to becoming associated with toxicosis is partially due to the strength of the previous association that forms between the recovery flavor and the experience of becoming well. This association apparently takes precedence over other relationships that may subsequently develop between the flavor paired with recovery and any gastrointestinal event, including malaise. However, when the procedure used by Buskist et al. (1980) to produce these recovery effects is closely examined, an alternative explanation is suggested. The important aspect of their procedure involved exposing both thiamine-supplemented and thiamine-deficient animals to a 5-day "recovery period" consisting of concurrent access to a familiar, deficient diet and a novel-flavored, thiamine-enriched diet. During this period, deficient animals consumed a significantly greater amount of enriched diet than did supplemented animals (cf. Rodgers \& Rozin, 1966). The point to be made is that the deficient animals were necessarily more familiar with the enriched diet than were their supplemented counterparts by virtue of the fact of the larger volumes of food ingested. In light of the fact that an animal's familiarity with a novel diet has been shown to play a crucial role in the subsequent development of taste aversions (generally, the greater the familiarity with a flavor, the weaker is the aversion when the food is later paired with toxicosis; Domjan, 1977; Kalat \& Rozin, 1973; Revusky \& Bedarf, 1967), relative familiarity with the enriched diet rather than association of the flavor with recovery from vitamin deficiency may be the determining factor in the mitigation of taste aversion.

The present experiment was designed to test this notion by allowing supplemented and deficient animals to consume approximately equal amounts of a novel, enriched diet prior to injections of either lithium chloride $(\mathrm{LiCl})$ or saline.

\section{METHOD}

Twenty-one female albino rats were placed in individual wire-mesh cages $(24 \times 20 \times 19 \mathrm{~cm})$ at 21 days of age. The 
animals were housed inside a temperature-controlled room $\left(22^{\circ} \mathrm{C}\right)$ with a 12-h light-dark cycle. Securely positioned at the front corners of each cage were $60 \mathrm{~g}$ food cups. Subjects had free access to water; food was available for $23 \mathrm{~h}$ each day throughout all conditions of the experiment. The 1-h food-deprivation interval occurred at the same time daily and was utilized to weigh and replenish food cups for each animal.

A synthetic thiamine-deficient diet was placed in both food cups for the first 21 days of the experiment. The thiaminedeficient diet consisted of casein $(20 \%)$, corn oil (4\%), salt mix XIV (5\%), B-vitamin mix minus $\mathrm{B}_{1}(2 \%)$, vitamins $\mathrm{A}, \mathrm{D}$, and $E$ in corn oil $(1 \%)$, choline bitartrate $(1 \%)$, and sucrose $(67 \%)$. The seven rats in the supplemented group were given thiamine hydrochloride in their water $\left(10 \mathrm{mg} \mathrm{B} / \mathrm{HCl} /\right.$ liter $\left.\mathrm{H}_{2} \mathrm{O}\right)$ each day so that they never became thiamine deficient. The remaining 14 rats experience thiamine deprivation and constituted the recovery group. For the next 6 days (Days 22-27) rats were offered a new chocolate-flavored, thiamine-enriched (CE) diet. The CE diet consisted of thiamine-deficient diet with the addition of thiamine hydrochloride $(25 \mathrm{mg} / 500 \mathrm{~g}$ diet $)$ and chocolate fudge pudding mix $(170 \mathrm{~g} / 3,200 \mathrm{~g}$ diet $)$. This constituted the recovery period. At this point, rats in the recovery group were randomly assigned to one of two subgroups and matched on the basis of total $\mathrm{CE}$ consumption during the recovery period. At the beginning of Day 28, rats in the supplemented group (Group $\mathrm{S} / \mathrm{P}$ ) and one of the recovery groups (Group R/P) were injected with $.3 \mathrm{M} \mathrm{LiCl}$ (ip, per liter of physiological saline at $1 \%$ of body weight). The remaining recovery group (Group R/S) were injected with physiological saline (also ip at $1 \%$ body weight). All rats were subsequently offered the choice between the former, deficient diet and the CE diet for the next 4 days (Days 28-31).

\section{RESULTS AND DISCUSSION}

During the 6-day recovery period, rats in Group S/P consumed a mean of $78.20 \mathrm{~g}$ of $\mathrm{CE}$ diet, whereas the mean consumption of rats in Groups $\mathrm{R} / \mathrm{P}$ and $\mathrm{R} / \mathrm{S}$ was 75.84 and $71.80 \mathrm{~g}$, respectively. These differences were not statistically significant $[\mathrm{F}(2,18)=.447]$. The between-groups difference in $\mathrm{CE}$ consumption on the final day of recovery was also not significant $[F(2,18)=$ .137].

Figure 1 depicts the amount of CE diet consumed as a percentage of total dietary intake over the entire 4-day postpoisoning period (Days 28-31). During the initial 24-h postpoisoning span, $S / P$ rats consumed significantly less CE diet (only $4 \%$ of their total intake from the CE source) than did rats in Groups $\mathrm{R} / \mathrm{P}$ and $\mathrm{R} / \mathrm{S}[71 \%$ and $83 \%$ from the same source, respectively; $F(2,18)=38.59, p<.01]$. The Scheffe' test further indicated reliable differences between $\mathrm{S} / \mathrm{P}$ rats and both recovery groups $\left(\mathrm{S} / \mathrm{P}\right.$ vs. $\mathrm{R} / \mathrm{P}, \mathrm{F}_{\mathrm{s}}=48.71, \mathrm{p}<.01 ; \mathrm{S} / \mathrm{P}$ vs. $\left.\mathrm{R} / \mathrm{S}, \mathrm{F}_{\mathrm{S}}=65.77, \mathrm{p}<.01\right)$. No reliable difference was found between the recovery groups $\left(F_{s}=1.28\right)$. Figure 1 also shows that $\mathrm{R} / \mathrm{P}$ and $\mathrm{R} / \mathrm{S}$ rats continued to consume similar amounts of $\mathrm{CE}$ diet during the entire 4-day postinjection period, whereas $\mathrm{S} / \mathrm{P}$ rats showed a slight increase in $\mathrm{CE}$ consumption during the same period.

Consistent with earlier results from thiaminedeficient rats (Buskist et al., 1980; Zahorik, 1977; Zahorik \& Bean, 1975), the present investigation demonstrated that pairing LiCl-induced malaise with a food

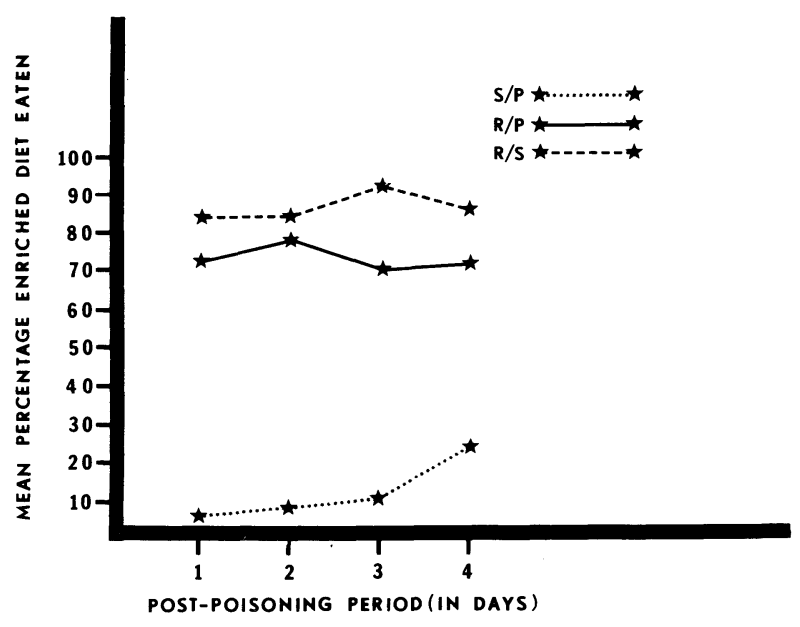

Figure 1. Mean percentage of $\mathrm{CE}$ diet consumed during the 4-day test period. Data are averages across subjects in each group. See text for further explanation.

(CE diet) whose associative history, up to that point, was clearly beneficial did not alter the preference for that food that was established during the recovery period. In contrast, rats that received an identical sequence of gustatory events, with the exception of being consistently thiamine supplemented ( $\mathrm{S} / \mathrm{P}$ rats), showed a marked aversion to the $\mathrm{CE}$ diet during the first 24-h postpoisoning period. Rats that were originally deficient, then recovered, and were subsequently injected with saline showed little or no aversion to the CE diet. Figure 1 shows that while $\mathbf{S} / \mathbf{P}$ rats slightly increased their $\mathrm{CE}$ diet consumption, both $\mathrm{R} / \mathrm{P}$ and $\mathrm{R} / \mathrm{S}$ rats' preference for the CE diet remained extremely stable throughout the 4-day postpoisoning period.

It has long been known that rats are particularly sensitive to the consequences of ingestion (see, e.g., Barnett, 1963). If ingestion is followed by an aversive or otherwise unusual event, a flavor aversion is learned. Conversely, if ingestion is followed by a "safe" experience, the rat learns that the food is nonaversive. It is a rat's learning that a food is safe that is generally believed to attenuate taste aversion conditioning (Kalat, 1977; Kalat \& Rozin, 1973). Moreover, a single safe experience with a food has been shown to greatly reduce its associability with toxicosis (Frumpkin, 1975).

In the present experiment, all groups of rats were exposed to the CE diet for 6 days. In contrast to the study by Buskist et al. (1980), in which deficient animals consumed greater amounts of enriched diet than did supplemented animals, deficient and supplemented animals in the present study consumed approximately equal amounts of the CE diet. Presumably, then, all groups were approximately equal in terms of their familiarity with the $\mathrm{CE}$ diet. $\mathrm{R} / \mathrm{S}$ and $\mathrm{R} / \mathrm{P}$ rats, however, also experienced recovery from thiamine deficiency while ingesting the CE diet. Had the CE diet become strictly familiar and safe for $\mathrm{R} / \mathrm{P}$ rats, they should have 
exhibited a toxicosis-induced aversion to the CE diet in much the same manner as $\mathrm{S} / \mathrm{P}$ rats. The fact that this did not occur, coupled with the finding that $R / P$ and $\mathrm{R} / \mathrm{S}$ rats consumed similar percentages of $\mathrm{CE}$ diet regard less of receiving $\mathrm{LiCl}$ or saline injections, strongly suggests that the context in which an animal is familiarized with foods is perhaps more crucial than is familiarity per se in the development of food selection and preference.

\section{REFERENCES}

Barker, L. M., Best, M. R., \& Domjan, M. (Eds.). Learning mechanisms in food selection. Waco, Tex: Baylor University Press, 1977.

Barnetr, S. A. The rat: $A$ study in behavior. Chicago: Aldine Press, 1963.

Buskist, W. F., Mille r, H. L., Duncan, P., \& Fleming, D. E. Associative history determines strength of taste-aversion conditioning in thiamine-deficient rats. Physiology \& Behavior, 1980, 25, 989-992.

Domjan, M. Attenuation and enhancement of neophobia for edible substances. In L. M. Barker, M. R. Best, \& M. Domjan (Eds.), Learning mechanisms in food selection. Waco, Tex: Baylor University Press, 1977.

FrUmpKIN, K. Failure of sodium- and calcium-deficient rats to acquire conditioned taste aversions to the object of their specific hunger. Journal of Comparative and Physiological Psychology, $1975,89,329-339$.
Garcia, J., Ervin, F. R., Yorke, C., \& Koelling, R. A. Conditioning with delayed vitamin injections. Science, 1967, 155, 716-718.

KaLAT, J. W. Status of "learned safety" or "learned noncorrelation" as a mechanism in taste aversion learning. In L. M. Barker, M. R. Best, \& M. Domjan (Eds.), Learning mechanisms in food selection. Waco, Tex: Baylor University Press, 1977.

KALAT, J. W., \& Rozin, P. "Learned-safety" as a mechanism in long-delay taste-aversion learning in rats. Journal of Comparative and Physiological Psychology, 1973, 83, 198-207.

Milgram, N. W., Krames, L., \& Alloway, T. M. (Eds.). Food aversion learning. New York: Plenum, 1977.

Revusky, S. H., \& Bedarf, E. W. Association of illness with ingestion of novel foods. Science, 1967, 155, 219-220.

Rodgers, W., \& Rozin, P. Novel food preference in thiaminedeficient rats. Journal of Comparative and Physiological Psychology, 1966, 61, 1-4.

ZAHORIK, D. M. Associative and non-associative factors in learned food preferences. In L. M. Barker, M. R. Best, \& M. Domjan (Eds.), Learning mechanisms in food selection. Waco, Tex: Baylor University Press, 1977.

ZAHORIK, D. M., \& BEAN, C. A. Resistance of "recovery" flavors to later association with illness. Bulletin of the Psychonomic Society, 1975, 6, 309-312.

Zahorik, D. M., \& MaIER, S. F. Appetitive conditioning with recovery from thiamine deficiency as the unconditoned stimulus. Psychonomic Science, 1969, 17, 309-310.

(Received for publication January 20, 1981.) 